\title{
O DESENVOLVIMENTO DA CAPACIDADE DE ARGUMENTAÇÃO EM MÍDIAS SOCIAIS DIGITAIS: O USO PEDAGÓGICO DO WHATSAPP
}

\author{
THE DEVELOPMENT OF ARGUMENTATIVE CAPACITY IN DIGITAL SOCIAL MEDIAS: \\ THE PEDAGOGICAL USE OF THE WHATSAPP
}

\section{EL DESARROLLO DE LA CAPACIDADAD DE ARGUMENTACIÓN EN MEDIOS SOCIALES DIGITALES: EL USO PEDAGÓGICO DEL WHATSAPP}

\author{
Erikson de Carvalho Martins ${ }^{1}$, Gilberto Lacerda Santos ${ }^{23}$
}

\section{RESUMO}

Este artigo tem por objetivo analisar a utilização pedagógica das mídias sociais digitais para o desenvolvimento da argumentação. Buscamos as contribuições teóricas de Wittgeinstein (1999) e Lyotard (2013), que dialogam sobre a construção dos variados jogos de linguagem na interação humana; de Barton e Lee (2015), Xavier e Lyra (2012) e Carvalho Martins (2015), que discorrem sobre a utilização dos espaços digitais para o desenvolvimento da postura/argumentação; e, por fim, de Perelman e Olbrechts-Tyteca (2005) e Leitão (2011), que abordam acerca das estratégias argumentativas. Com abordagem qualitativa, de cunho exploratório e com caraterísticas de uma pesquisa-ação, desenvolvemos como metodologia de estudo a aplicação de uma proposta de atividade pedagógica a 21 estudantes de uma turma do 20 ano do ensino médio técnico integrado na disciplina Língua Portuguesa. Essa atividade consistiu na discussão de um tema polêmico em uma mídia social digital escolhida pelos estudantes: o WhatsApp. Os dados coletados foram analisados sob a ótica da análise de conteúdo (Bardin, 2009) para a compreensão e interpretação das mensagens postadas no grupo do aplicativo. Finalmente, apontamos que é possível utilizar os espaços de escrita online oferecidos por diversas mídias sociais digitais para o desenvolvimento da argumentação dos estudantes, estimulando-os a discutirem, a apresentarem um posicionamento crítico e a construírem diversos argumentos para defendê-lo.

PALAVRAS-CHAVE: Argumentação. Mídias Sociais Digitais. WhatsApp. Proposta Pedagógica.

\begin{abstract}
This article aims to analyze the pedagogical use, of the social digital medias to the development of argumentation. We look for theoratical contributions of Wittgeinstein (1999) e Lyotard (2013), who discuss the construction of the various language games in human interaction; of Barton \& Lee (2015), Xavier \& Lyra (2012) and Carvalho Martins (2015), who talk about the use of digital spaces for the development of posture/argumentation; and, finally, of Perelman \& Olbrechts-Tyteca (2005) and Leitão (2011), that approach about the argumentative strategies. With qualitative approach, of exploratory intent and with action research features, we developed as studying methodology the application of a pedagogical activity proposal to 21 students of the second year of a technician high school in the discipline of Portuguese Language. This activity consisted in the discussion about a polemic theme in a social digital media choosed by the students: The WhatsApp. The data collected were analysed from the content analysis viewpoint (Bardin, 2009), to understand and interpret the messages posted on the group of the App. Finally, we indicate that is possible to use the spaces of online writing offered by several social digital medias to the development of the student's argument, stimulating them to discuss, to show a critical positioning and build several arguments to defend them.
\end{abstract}

\footnotetext{
${ }^{1}$ Doutorando em Educação - Universidade de Brasília (UnB) - Brasília, DF. Brasil - Professor de Língua Portuguesa - Instituto Federal de Educação, Ciência e Tecnologia da Bahia (IFBA) Salvador - BA - Campus Barreiras. E-mail: eriksonecm@hotmail.com

2 Doutor em Sociologia - Universidade de Brasília (UnB) - Brasília, DF. Brasil - Professor Titular do Departamento de Métodos e Técnicas da Faculdade de Educação da Universidade de Brasília (UnB) - Brasília, DF. Brasil. E-mail: gilberto.lacerda.santos@gmail.com

Submetido em: 10/12/2016- Aceito em: 19/10/2017
}

(C) ETD-Educação Temática Digital Campinas, SP $\quad$ v.20 $\quad$ n.1 $\quad$ p. 137-152 jan./mar. 2018


KEYWORDS: Argumentation. Social Digital Medias. WhatsApp. Pedagogical Proposal.

\section{RESUMEN}

Este artículo tiene como objetivo analizar el uso educativo de las redes sociales digitales para el desarrollo de la argumentación. Buscamos las aportaciones teóricas de Wittgeinstein (1999) e Lyotard (2013), que dalogan sobre la construcción de los variados juegos de lenguaje en la interacción humana; de Barton y Lee (2015), Xavier y Lyra (2012) y Carvalho Martins (2015), que discuten el uso de los espacios digitales para el desarrollo de la postura / argumentación; y, por último, Perelman y Olbrechts-Tyteca (2005) y Leitão (2011), que discuten acerca de las estrategias de argumentación. Con un enfoque cualitativo, de naturaleza exploratoria y características de una investigación-acción, desarrollamos como metodología de estudio la aplicación de una propuesta para la actividad educativa a 21 estudiantes en una clase de segundo año de la enseñanza media técnica integrada en la asignatura de Lengua Portuguesa. Esta actividad se formó en la discusión de un tema controvertido em un medio social digital elegido por los estudiantes: WhatsApp. Los datos fueron analizados desde la perspectiva de análisis del contenido (Bardin, 2009) para comprender e interpretar los mensajes nuevos en el grupo de aplicaciones. Por fin, señalamos que se pueden utilizar los espacios de escrita online que ofrecen los distintos medios sociales digitales para el desarrollo de la argumentación de los estudiantes, animándoles a discutir, presentar un posicionamiento crítico y a construir varios argumentos para defenderlo.

PALABRAS CLAVE: Argumentación. Medios Sociales Digitales. WhatsApp. Propuesta Pedagógica.

\section{INTRODUÇÃO}

A expansão das tecnologias de informação, comunicação e expressão (TICE), a ampliação do acesso à Internet e o desenvolvimento de mídias sociais digitais, a exemplo de sites de redes sociais e aplicativos diversos para computadores e smartphones, possibilitam aos indivíduos novas formas de comunicação e interação, facilitam o acesso a informações e contribuem para a construção e disseminação de conhecimentos na Pós-Modernidade.

Informar, conhecer, comunicar, interagir, expressar, disseminar, dentre outras muitas ações possíveis dentro e fora de contextos tecnológicos são apenas viáveis por meio da linguagem. É ela o motor que impulsiona a vida em sociedade, sendo essencial para o seu desenvolvimento, modificando-se e se adaptando aos contextos e suas transformações ao longo dos tempos, mostrando, assim, toda a sua força e vivacidade.

Dessa forma, observamos como as tecnologias digitais modificaram as relações que os indivíduos estabelecem com a leitura e a escrita, proporcionando o contato com textos multimodais, bem como oferecendo novos espaços de escrita online, como apontam Barton e Lee (2015). Nesses espaços, como aplicativos de mensagens instantâneas, blogs, revistas eletrônicas, sites de relacionamento e sites de redes sociais, por exemplo, é possível observar a utilização da escrita para divulgar conhecimentos, postar comentários, fazer reflexões e relatos pessoais, debater com outras pessoas, entre outras atividades, utilizando-se não só da modalidade de linguagem verbal, como também da linguagem nãoverbal. Para Barton e Lee (2015), esses espaços de escrita online também possibilitam às pessoas o compartilhamento, a avaliação e a produção de opiniões públicas, o que os autores denominam de postura, ou seja, um posicionamento acerca daquilo que é dito. 
Lyotard (2013) sinaliza que uma das características da pós-modernidade é a consideração da existência dos diversos jogos de linguagem, conceito elaborado por Wittgeinstein e utilizado por Lyotard para a análise da legitimação do conhecimento científico no cenário pós-moderno. Como jogos de linguagem podemos denominar as variadas formas de organização de enunciados para atingir fins específicos. Em cada jogo de linguagem, as palavras são organizadas em enunciados e seus significados podem ser modificados a depender do contexto em que são utilizadas. Portanto, podemos dizer que narrar, orientar, descrever, prescrever, argumentar e tantas outras ações linguísticas realizadas dentro e fora dos espaços de escrita online são consideradas como exemplos dos inúmeros jogos de linguagem existentes.

Associando a argumentação ao conceito de postura (BARTON e LEE, 2015) e a um dos diferentes jogos de linguagem da pós-modernidade (WITTGEINSTEIN, 1999; LYOTARD, 2013), partimos do pressuposto de que as mídias sociais digitais, como sites de redes socia is (Facebook, Youtube, Instagram, Twitter) e aplicativos de mensagens instantâneas (WhatsApp, Messenger, Snapchat, Telegram) podem ser espaços de escrita onde a capacidade de argumentar pode ser incentivada e desenvolvida.

Tendo em vista o exposto, este trabalho busca responder ao seguinte questionamento: De que forma as mídias sociais digitais podem ser pedagogicamente utilizadas para o desenvolvimento da capacidade de argumentação dos estudantes? Dessa forma, o estudo em torno dessa questão tem como objetivo analisar a utilização pedagógica das mídias sociais digitais para o desenvolvimento da argumentação. Como metodologia de estudo desenvolvemos uma proposta de atividade pedagógica com 21 estudantes de uma turma do 20 ano do ensino médio técnico integrado, que consistiu na discussão de um tema polêmico em uma mídia social digital escolhida pelos estudantes: o aplicativo de mensagens instantâneas WhatsApp. Dentro de um grupo criado especificamente para o desenvolvimento da atividade no aplicativo, foram apresentados diversos links para leitura de textos, apreciação de vídeos e imagens sobre o tema a ser debatido. Em seguida, os estudantes foram orientados a apresentar o seu posicionamento acerca da problemática em questão, defendendo-o por meio de argumentos para os colegas.

Este artigo está dividido em quatro momentos. Primeiramente, discutimos sobre a importância da construção dos jogos de linguagem para a interação e comunicação humana. Em seguida, discorremos sobre a argumentação como um dos jogos de linguagem produzido nas mídias sociais digitais. Depois, apresentamos a metodologia de trabalho e discutimos os resultados encontrados. Por fim, tecemos as considerações finais sobre a possibilidade de desenvolvimento da capacidade de argumentar nas mídias sociais digitais. 


\title{
2 OS MÚLTIPLOS JOGOS DE LINGUAGEM DE WITTGEINSTEIN
}

Segundo Wittgeinstein (1999), grande filósofo do século XX e um dos idealizadores da virada linguística ${ }^{4}$, a linguagem é uma atividade humana social, cultural e historicamente situada. Isso quer dizer que as palavras não possuem significados estanques, mas sentidos e funções práticas que vão se construindo no contexto em que são utilizadas, constituindo-se, assim, como formas de vida. Por essa razão, não é possível falar em uma única linguagem, mas sim em "jogos de linguagem", utilizados para narrar, descrever, prescrever, traduzir, ordenar, argumentar, persuadir, entre outras funções.

Dessa forma, a linguagem não pode ser concebida como algo lógico e formal, por isso um jogo de linguagem não pode ser definido claramente, o que pode ser feito é uma análise das características similares entre diversos jogos de linguagem. Inter-relacionando pensamento, linguagem e mundo, Wittgeinstein (1999) ressalta que "a filosofia é uma luta contra o enfeitiçamento do nosso entendimento pelos meios da nossa linguagem" (1999, p.65). Para Lyotard (2013), em seus estudos acerca da Pós-Modernidade, a análise do problema da legitimação do conhecimento científico centra-se nos aspectos pragmáticos da linguagem, em especial no conceito de "jogos de linguagem" desenvolvido por Wittgeinstein.

\begin{abstract}
Quando Wittgeinstein, recomeçando o estudo da linguagem a partir do zero, centraliza sua atenção sobre os efeitos dos discursos, chama os diversos tipos de enunciados que ele caracteriza desta maneira, e dos quais enumerou-se alguns, de jogos de linguagem. Por este termo quer dizer que cada uma destas diversas categorias de enunciados deve poder ser determinada por regras que especifiquem suas propriedades e o uso que delas se pode fazer, exatamente como o jogo de xadrez se define como um conjunto de regras que determinam as propriedades das peças, ou o modo conveniente de destacá-las. (LYOTARD, 2013, p. 16-17)
\end{abstract}

Nesses termos, Lyotard (2013) considera que o saber científico, assim como os demais tipos de conhecimento, nada mais é que um discurso, um jogo de linguagem que possui suas regras próprias, como um contrato entre os jogadores para seguir as regras estabelecidas. Qualquer enunciado construído que fuja às regras não faz parte do jogo, pois "todo enunciado deve ser considerado como um lance feito num jogo" (p.17). De acordo com Lyotard (2013), os atos de linguagem fazem parte de uma agonística geral, um jogo dialético com base na argumentação, no intuito de jogar com as palavras realizando novas construções, não para ganhar, mas para simplesmente jogar.

\footnotetext{
${ }^{4}$ Novo paradigma estabelecido a partir do século XX que enfatizou como um dos objetos de investigação filosófica o predomínio da linguagem sobre o pensamento.
}

(C) ETD-Educação Temática Digital Campinas, SP $\quad$ v.20 $\quad$ n.1 $\quad$ p. 137-152 jan./mar. 2018 
No uso ordinário do discurso, numa discussão entre dois amigos, por exemplo, os interlocutores lançam mão de todo os meios, mudam de jogo entre um enunciado e outro: a interrogação, a súplica, a asserção, o relato são lançados confusamente na batalha. Esta não é desprovida de regra, mas sua regra autoriza e encoraja a maior flexibilidade dos enunciados. (LYOTARD, 2013, p. 31).

No contexto de uma sociedade dita informacional, com avanços tecnológicos significativos, observamos como a produção e a transmissão dos conhecimentos sofreram inúmeras modificações. No que tange à área da comunicação, com a produção de ferramentas de mídias sociais, sites de redes social, aplicativos diversos para smartphones, entre outros, por exemplo, torna-se imprescindível que os efeitos da linguagem possam ser considerados e assumam uma grande importância, pois como aponta Lyotard (2013) a linguagem é o vínculo social nas sociedades mais desenvolvidas e não assume, como na perspectiva tradicional, apenas as funções de comunicação e informação.

São os variados jogos de linguagem que entram em cena, com suas regras postas e lances feitos, possibilitando a construção de discursos que legitimam a produção de conhecimentos e determinam as relações de poder. Como afirma Lyotard (2013), "as disputas serão então construídas por conhecimentos (ou informações) e a reserva de conhecimentos, que é a reserva da língua em enunciados possíveis, é inesgotável" (p.120). Assim, considerando a argumentação como um dos múltiplos jogos de linguagem bastante produzido no contexto das tecnologias digitais, abordamos a seguir acerca do potencial das mídias sociais digitais para a construção da capacidade de argumentar.

\section{A CAPACIDADE DE ARGUMENTAÇÃO NAS MÍDIAS SOCIAIS DIGITAIS}

A inserção de diferentes gêneros textuais digitais (blog, fórum, chat, lista de discussão, etc.), de sites de redes sociais (Facebook, Twitter, Instagram, Youtube, entre outras) e de aplicativos de mensagens instantâneas (WhatsApp, Snapchat e Hangouts, por exemplo) nas atividades pedagógicas podem possibilitar uma maior interação entre os estudantes, bem como desenvolver aspectos da argumentação imprescindíveis para o desenvolvimento de indivíduos com pensamento crítico-reflexivo sobre o mundo que os cercam.

Para Umbelina (2012) os sites de redes sociais não podem ser ignorados e desconsiderados pelas práticas pedagógicas dos professores, uma vez que fazem parte do cotidiano de uma grande maioria de estudantes. Para a pesquisadora, o que interessa é que as redes sociais podem ser introduzidas no cotidiano da escola, desde que as propostas sejam inseridas de forma planejada, segura e produtiva, contribuindo para a aprendizagem dos educandos.

Nesse sentido, não basta apenas a simples utilização das mídias sociais digitais, é preciso uma mudança de postura do educador frente a essa nova demanda e o

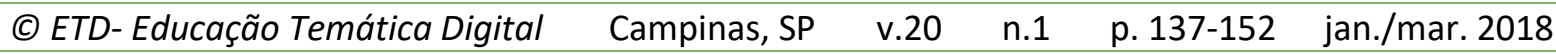


planejamento de ações que sejam cuidadosamente pensadas, visando à aprendizagem dos estudantes. Para Kenski (2003), a nova era digital não gera somente o uso de novos equipamentos para a apreensão, construção e socialização do conhecimento, produz também novas possibilidades de aprendizagem, novas racionalidades, novos estímulos para perceber o mundo.

Segundo Kenski (2013), temos hoje uma tecnologia de ponta, porém muitas práticas pedagógicas ainda continuam anacrônicas e não levam em conta o potencial pedagógico das novas tecnologias digitais para a participação e a interação.

\begin{abstract}
A necessidade, portanto, não é de usar o meio para continuar fazendo o mesmo. É preciso mudar as práticas e os hábitos docentes e aprender a trabalhar pedagogicamente de forma lúdica e desafiadora, com o apoio e a mediação de softwares, programas especiais e ambientes virtuais. Em princípio, devemos compreender e nos apropriar das especificidades das inovações tecnológicas, adequando-as como inovações pedagógicas. (KENSKI, 2013, p. 97).
\end{abstract}

No que tange ao desenvolvimento da argumentação, Xavier e Lyra (2012) destacam que as estratégias argumentativas se estendem de forma natural aos gêneros emergentes em meio às novas tecnologias e a todos os seus recursos. Por essa razão, a argumentação poderia ser estimulada e trabalhada pelos professores a partir de iniciativas de propostas de produção textual de gêneros textuais digitais na rede, sendo alguns desses já conhecidos e utilizados por grande parte dos estudantes, como o chat, por exemplo, produzido em sites de redes sociais e aplicativos de mensagens instantâneas diversos. A expansão natural da argumentação para o chat, por exemplo, se dá em meio às próprias propostas de trabalho muitas vezes desenvolvidas com o gênero, como a discussão de temas polêmicos, que despertam nos estudantes a formulação de um ponto de vista e a seleção de argumentos para persuadir e convencer seus pares no decorrer do debate, como sinaliza Carvalho Martins (2015).

Perelman e Olbrechts-Tyteca (2005) desenvolveram uma abordagem retórica da argumentação que objetiva investigar as práticas discursivas que provocam ou aumentam a adesão dos espíritos. Para eles, as práticas argumentativas devem ser ensinadas e praticadas a fim de que o locutor consiga motivar, influenciar, conquistar e persuadir o auditório pelo discurso. Assim, a argumentação é concebida como um fenômeno flexível, dinâmico, sujeito a variações, transformações, ampliações e intervenções dos sujeitos envolvidos no processo. A argumentação consiste em:

provocar ou aumentar a adesão dos espíritos às teses que se apresentam a seu assentimento: uma argumentação eficaz é a que consegue aumentar essa intensidade de adesão, de forma que se desencadeie nos ouvintes a ação pretendida (ação positiva ou abstenção) ou, pelo menos crie neles uma disposição para a ação que se manifestará no momento oportuno. (PERELMAN e OLBRECHTS-TYTECA, 2005, p. 50) 
Portanto, diante dessa flexibilidade e dinamicidade da argumentação apresentadas por Perelman e Olbrechts-Tyteca (2005), podemos considerá-la como um dos jogos de linguagem mencionados por Wittgeinstein (1999) em sua filosofia e apropriados por Lyotard (2013) para análise dos discursos na pós-modernidade, cujos lances são feitos na forma como as palavras são organizadas e sofrem transformações de sentido na construção dos diversos enunciados a depender do contexto em que são utilizadas e das relações estabelecidas entre enunciador e destinatário.

É interessante destacar o importante papel concedido por Perelman e OlbrechtsTyteca (2005) à linguagem, reafirmando seu papel social, considerando-a como instrumento de comunicação e, sobretudo, de ação sobre os indivíduos. Além disso, os autores enfatizam a necessidade de a linguagem estar associada a um contexto real, uma vez que ela faz parte das tradições de uma comunidade. Portanto, torna-se imprescindível que atividades de estímulo à argumentação possam ser desenvolvidas em ambientes digitais, contexto atual de uso efetivo da linguagem e de realização de práticas sociais por uma grande parcela de educandos.

No contexto das tecnologias digitais, uma nomenclatura que merece destaque nas discussões sobre argumentação diz respeito ao conceito de postura. Para Barton e Lee (2015), esse conceito da linguística acopla muitos trabalhos que objetivam compreender a significação dos enunciados produzidos pelos falantes e/ou escritores nos ambientes de escrita online. Os autores definem postura "como um posicionamento de um falante em relação ao que é dito e a quem o enunciado é dirigido" (p. 49). A postura se refere à forma como os pontos de vista são expressos na mídia online. A própria estrutura e os recursos de algumas mídias oportunizam o desenvolvimento de postura, instigando a discussão, a expressão de opiniões, a produção e o compartilhamento de conhecimentos, como a plataforma do Facebook e do Youtube, que possibilita a postagem de comentários, e a do WhatsApp, que permite responder a mensagens específicas em grupos de discussão.

Nos ambientes digitais, o papel do professor como mediador e a participação dos estudantes nas discussões propostas para desenvolvimento de postura configuram as categorias de ações discursivas defendidas por Leitão (2011), sendo elas pragmáticas, argumentativas e epistêmicas. Nas discussões propostas nesses ambientes, essas ações discursivas se apresentam como um estímulo para que os estudantes apresentem seu ponto de vista, justificando-se, motivando-os a debaterem (ações pragmáticas). Além disso, temos a formulação de argumentos, o levantamento de dúvidas e a avaliação de contraargumentos (ações argumentativas), bem como a utilização de informações, terminologias, procedimentos, habilidades e modos de pensamento específicos da área de concentração do tema em debate (ações epistêmicas).

Portanto, o desenvolvimento da argumentação pode se fazer presente na leitura e produção textual mediadas pelas novas tecnologias digitais, representando para os 
professores a possibilidade de promover para os estudantes momentos de participação ativa, troca de informações, produção de conhecimentos de forma colaborativa, além de possibilitar o estímulo ao desenvolvimento da argumentação através da exposição e justificação de ideias e construção e avaliação de argumentos, contribuindo, assim, para a formação de sujeitos ativos, crítico-reflexivos e co-construtores do conhecimento.

\section{METODOLOGIA DE TRABALHO}

O estudo apresentado neste trabalho é de abordagem qualitativa, com viés exploratório, e, quanto aos procedimentos, possui características de uma pesquisa-ação, pois como destaca Thiollent (2002), a pesquisa-ação se configura como uma investigação social com estreita relação com a ação, na qual pesquisadores e participantes se envolvem de modo participativo e cooperativo para transformação de uma realidade ou solução de um problema. Ainda para o autor, nesse tipo de pesquisa "os pesquisadores em educação estariam em condição de produzir informações e conhecimentos de uso mais efetivo, inclusive ao nível pedagógico" (2002, p. 75).

A metodologia de estudo consistiu na aplicação de uma proposta de atividade pedagógica a 21 estudantes de uma turma do 20 ano do ensino médio técnico integrado na disciplina Língua Portuguesa. Os estudantes foram convidados pelo professor-pesquisador via WhatsApp, no grupo de comunicação da turma, a participarem de uma atividade de discussão, com duração de 03 dias, sobre um tema polêmico em uma mídia social digital, dando-Ihes como alternativas de escolha o Facebook, o WhatsApp, o Youtube e o Messenger, mídias mais populares entre eles, possibilitando, ainda, que pudessem dar sugestões de outras mídias sociais caso não optassem por alguma das mencionadas. A turma, composta por 24 alunos, foi convidada para a atividade. Desse total, 21 deles participaram da votação, mostrando-se favoráveis à proposta e escolhendo entre as mídias apresentadas, sem indicação de nenhuma outra sugestão. O resultado da votação mostrou a preferência dos estudantes pelo WhatsApp (14 votos), seguido pelo Facebook (04 votos), do Youtube (02 votos) e, por último, do Messenger (01 voto).

Dada a escolha dos estudantes pelo desenvolvimento da atividade com o aplicativo de mensagens instantâneas WhatsApp, foi criado um grupo na referida mídia social denominado "Interagindo e Argumentando" para apresentação da proposta pedagógica, indicação de links para leitura e realização das discussões. A temática escolhida pelo professor foi "A reforma do Ensino Médio pela MP 746/2016", assunto bastante discutido no cenário atual e de bastante interesse dos próprios estudantes.

Os dados coletados a partir da aplicação da proposta de atividade pedagógica supracitada foram analisados sob a ótica da análise do conteúdo que, segundo Bardin (2009), representa um conjunto de procedimentos de análise das comunicações que utiliza técnicas sistemáticas e objetivas de descrição do conteúdo das mensagens. Franco (2003), 
por sua vez, refere-se à análise de conteúdo como uma estratégia de pesquisa que tem como ponto de partida a mensagem e que se situa em uma delimitação mais ampla da comunicação. Isto posto, a análise de conteúdo aqui desenvolvida foi realizada a partir das mensagens postadas pelos estudantes durante as interações no grupo de discussão do WhatsApp, conforme verificamos na seção que se segue.

\section{ANÁLISE DOS RESULTADOS}

A atividade realizada em seus 03 dias de duração, de 31/10 a 02/11/2016, contou com 138 sequências dialogais realizadas na forma de turnos de fala. Dentre essas sequências, 16 foram do professor-pesquisador, atuando como mediador das discussões com questionamentos sobre o tema em questão, orientações e esclarecimentos de dúvidas sobre a atividade. Somente 07 sequências dialogais fugiram do tópico de discussão, com mensagens sobre "retorno das aulas", "viagens" e "saída para o trabalho". As demais interações focalizaram no tema discutido: a reforma do ensino médio.

Dado o exposto, analisamos nesta seção as sequências dialogais construídas por 12 estudantes integrantes do grupo (07 participantes ativos e 05 estudantes que publicaram uma única vez $)^{5}$, dando uma maior ênfase às participações ativas, pois como reforçam Perelman e Olbrechts-Tyteca (2005), a construção da argumentação se dá por meio do debate entre os pares, visando a persuasão por meio do discurso. Nesse sentido, realizamos a análise de conteúdo a partir de 03 categorias distintas: 1) o posicionamento/a postura dos interlocutores acerca do tópico de discussão; 2) a variedade de jogos de linguagem construídos nas discussões e 3) a tipologia dos argumentos construídos. Com relação à última categoria, apoiamo-nos mais uma vez em Perelman e Olbrechts-Tyteca (2005), que estabelecem uma tipologia para classificação dos argumentos.

Examinando a primeira categoria - o posicionamento/a postura dos interlocutores acerca do tópico de discussão -, verificamos que apenas 02 estudantes defenderam um ponto de vista favorável à reforma do ensino médio, apresentando vários argumentos que embasam seus posicionamentos, como, por exemplo, os apresentados nas figuras 4 e 5 a seguir:

\footnotetext{
${ }^{5}$ A atividade pedagógica foi proposta, inicialmente, a 24 estudantes que compõem uma turma de 20 ano do ensino médio técnico integrado. Desses estudantes, 21 aceitaram participar da atividade e 03 não se manifestaram. Porém, dentre os 21 estudantes, apenas 15 postaram mensagens no grupo e 06 não interagiram, não apresentando nenhuma justificativa pela ausência nas discussões, uma vez que a participação na atividade era voluntária. Dentre os 15 alunos que publicaram no grupo, apenas 07 participaram de forma ativa, discutindo com os colegas, defendendo pontos de vista sobre a problemática e apresentando argumentos. 05 desses alunos apenas postaram uma única mensagem, sem interagir com os colegas, como se fosse apenas uma forma de cumprir com a atividade proposta para não deixar sem fazê-la. Finalmente, 3 alunos somente sinalizaram uma mensagem de "ok/beleza” para as postagens dos colegas.
} 
dependem de todas as discipınas e nao somente se resume a duas ou uma parcela. Não se descarta como essas disciplinas são fundamentais, pois a sociologia, por exemplo, auxilia no processo de discussão social. ㅁ. Por que uma reforma no ensino médio e não no fundamental? Há uma urgência social no Brasil que é o controle da evasão escolar que acontece enormemente no ensino médio durante a adolescência por isso tal foco no ensino médio, mas não podemos nos esquecer da urgência educacional que ocorre em todo o sistema educativo.

FIGURA 4 - Argumento do Estudante $\mathrm{H}$ Fonte: https://web.whatsapp.com/

Nos argumentos apresentados acima, observamos que os estudantes apontam que a reforma do ensino médio pode ser uma alternativa para a redução da evasão escolar que acontece nesse período de estudos, bem como uma melhoria da qualidade de educação, atingindo as metas estipuladas nos planos nacionais. É importante destacar que apesar desses estudantes apresentarem posicionamentos favoráveis à reforma, não deixaram de apontar em outros momentos das discussões que ela é polêmica e precisa de ajustes, especialmente no que diz respeito à grade de disciplinas e ao ensino integral.

Sob outra perspectiva, 10 estudantes exprimiram uma postura contrária à MP da reforma do ensino médio, explicitando a falta de diálogo do governo com a população, a retirada da obrigatoriedade de algumas disciplinas, o aumento da carga horária anual, as relações entre a MP 746 e a PEC 241/55, a falta de estrutura física das escolas para o ensino integral, dentre outras questões. As figuras 6 e 7, abaixo, mostram um pouco das discussões realizadas entre os estudantes. 


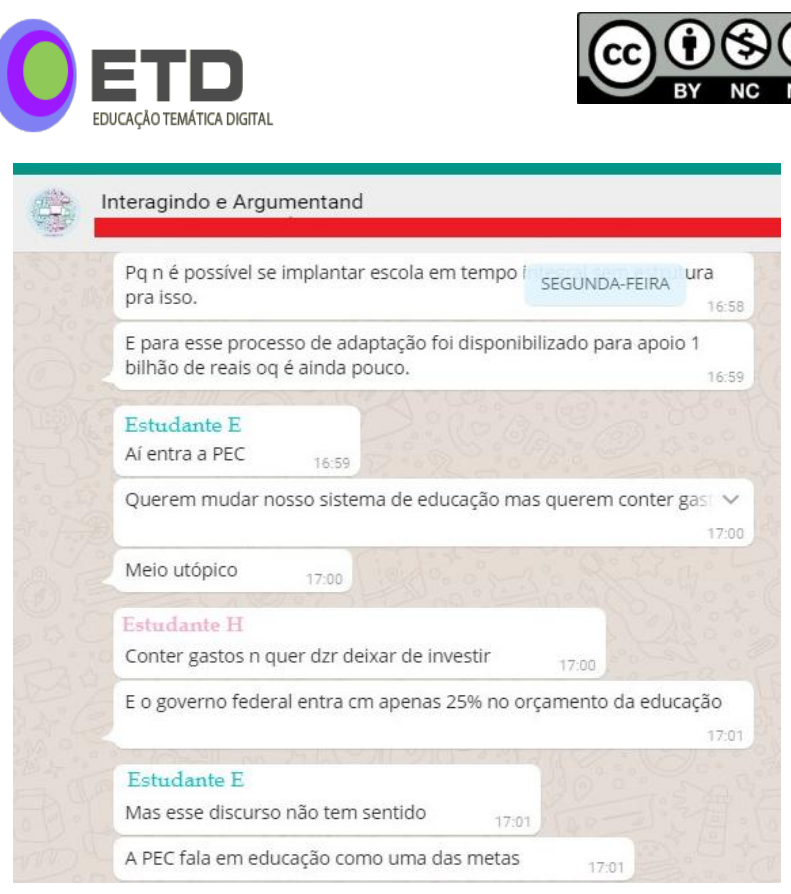

FIGURA 6 - Discussão no grupo

Fonte: https://web.whatsapp.com/
ARTIGO

DOI 10.20396/etd.v20i1.8647934

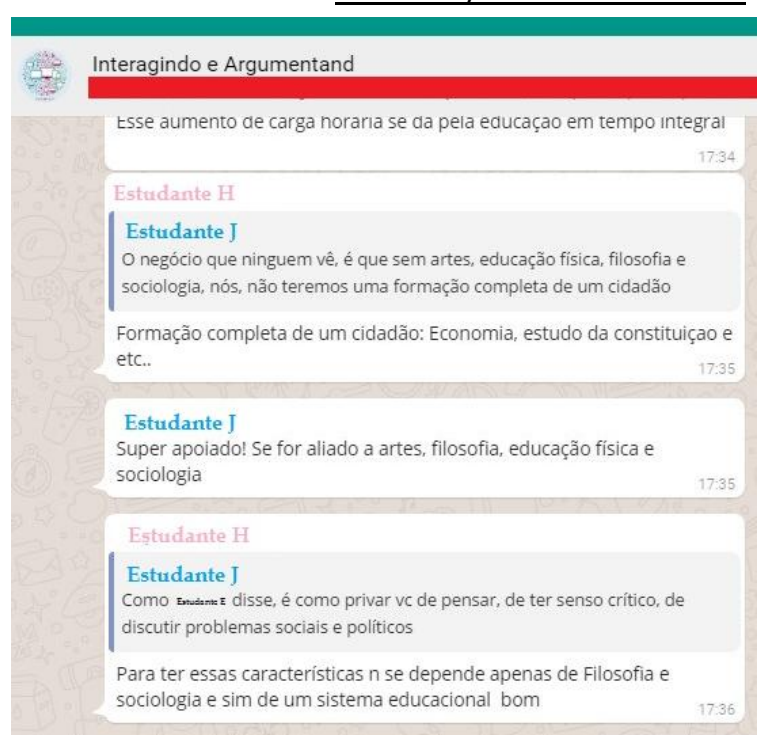

FIGURA 7 - Discussão no grupo

Fonte: https://web.whatsapp.com/

As figura 6 apresenta uma discussão entre os estudantes $E$ e $H$ a respeito da proposta de corte de gastos da PEC 241/55 e seu impacto na educação, contrapondo-a com o objetivo de melhoria de qualidade da educação a partir da reforma do ensino médio. $\mathrm{Na}$ figura 7, os estudantes $\mathrm{H}$ e J debatem sobre a não obrigatoriedade das disciplinas artes, filosofia, sociologia e educação física na proposta da medida provisória. O estudante $\mathrm{H}$ argumenta que elas não são essenciais para a formação completa do indivíduo, justificando que ele pode adquirir essa formação a partir do estudo de outras áreas do conhecimento. Por sua vez, o estudante J ressalta que as indicações do colega são pertinentes desde que estejam relacionadas às referidas disciplinas. É importante destacar como o estudante $\mathrm{H} \mathrm{e}$ outros estudantes utilizaram o recurso de citação do WhatsApp para apresentar concordância, dissentimento ou questionamento a respeito do que foi dito pelos colegas, utilizando a citação como base para expressão do seu ponto de vista e construção da argumentação.

Com relação à variedade de jogos de linguagem construídos nas discussões segunda categoria - constatamos que os estudantes produziram enunciados diversos com finalidades também distintas, utilizando quase sempre as mesmas palavras. Lyotard (2013) relembra que os jogos de linguagem, objeto de estudo de Wittgeinstein, estão ligados à vida real e construídos de forma contextualizada, em que as palavras assumem sentidos diferentes na construção de lances, levando em conta o referente, o enunciador e o destinatário. Antes de especificarmos alguns dos jogos de linguagem produzidos pelos estudantes na discussão da temática, demonstramos, abaixo, quais foram os vocábulos mais utilizados por eles em suas construções, conforme mostra a figura 08 . 


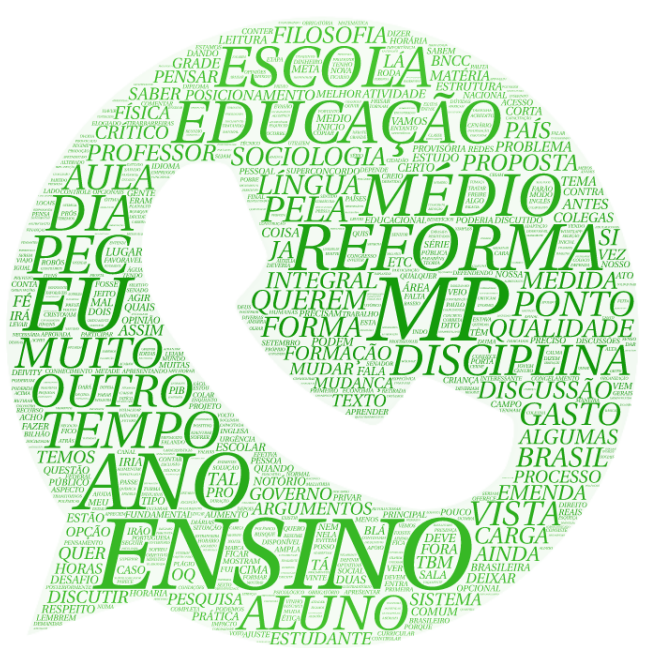

FIGURA 8 - Nuvem de palavras Fonte: https://tagul.com/

A figura 8 apresenta uma nuvem de palavras criada a partir das discussões realizadas entre os estudantes no grupo, evidenciando os vocábulos mais utilizados por eles na criação dos enunciados. A nuvem de palavras foi criada no site Tagul, que permite a escolha do formato da nuvem e a edição/seleção de palavras. Por essa razão, optamos pelo logotipo do WhatsApp, aplicativo escolhido pelos educandos, e excluímos da nuvem apenas números, nomes pessoais e alguns conectivos (preposições e conjunções), que apesar de importantes para a construção da coesão textual, não possuem uma carga informativa essencial para uma compreensão mais ampla do sentido do texto, como acontece com o substantivo, o adjetivo e outras classes de palavras. Dentre os vocábulos mais utilizados, destacam-se: escola, educação, ensino, médio, aluno, reforma, ano, PEC, MP, tempo, disciplina, entre outros utilizados para a elaboração dos jogos de linguagem.

No debate realizado entre os estudantes, verificamos a elaboração de diversos jogos de linguagem com vistas à defesa de um ponto de vista, ao estímulo das discussões e à apresentação de argumentos. Dessa forma, como exemplos desses jogos, podemos citar a interrogação ("E pra melhorar essa qualidade n é preciso uma reforma?" - Estudante $\mathrm{H}$ ), a afirmação ("A partir do momento que eles querem uma escola sem partido, eles querem jovens não pensantes" - Estudante K), a injunção ("olhem esse link ai" - Estudante J), o relato ("é normal aqui em Tecnópolis ${ }^{6}$ nas escolas públicas do ensino fundamental o professor de uma disciplina específica dando aula de outra por apenas ter um conhecimento básico" - Estudante M), a avaliação ("Para mim, a MP deveria ter sido discutida abertamente com a sociedade Sinceramente, são mudanças q pegaram os brasileiros de surpresa" - Estudante I), dentre muitos outros jogos construídos como lances no processo argumentativo.

\footnotetext{
${ }^{6}$ Nome fantasia da cidade relatada. 
Quanto à tipologia dos argumentos construídos - terceira e última categoria -, averiguamos que os estudantes utilizaram diferentes tipos de argumentos nas discussões efetivadas, visando marcar seu posicionamento e persuadir os colegas. Dentre os argumentos usados, estão os que exprimem: sucessão, comparação, contradição e incompatibilidade, inclusão ou divisão, identidade e definição, autoridade, dissociação, ilustração, entre outros tipos. O quadro 1, a seguir, apresenta alguns exemplos de argumentos elaborados pelos educandos e suas respectivas classificações de acordo com Perelman e Olbrechts-Tyteca (2005).

QUADRO 1 - Tipologia dos argumentos construídos pelos estudantes

\begin{tabular}{|c|c|c|}
\hline & ARGUMENTOS CONSTRUÍDOS & TIPOLOGIA \\
\hline 01 & $\begin{array}{l}\text { "A MP trata da reforma do ensino médio, a qual traz o jovem/estudante como } \\
\text { o centro da educação, dando ao mesmo a opção de escolha dentre algumas } \\
\text { disciplinas, inserindo o ensino em tempo integral, aumentando assim } \\
\text { consequentemente a carga horaria e disponibilizando de trabalho como } \\
\text { professor a pessoas de notório saber" - Estudante } \mathrm{H}\end{array}$ & SUCESSÃO \\
\hline 02 & $\begin{array}{l}\text { "Eles querem reformar o ensino médio, e ao mesmo tempo querem corta os } \\
\text { gastos públicos... fico muito contraditório isso" - Estudante K }\end{array}$ & $\begin{array}{l}\text { CONTRADIÇÃO E } \\
\text { INCOMPATIBILIDADE }\end{array}$ \\
\hline 03 & $\begin{array}{l}\text { "Formação completa de um cidadão: Economia, estudo da constituiçao e etc." } \\
\text { - Estudante H }\end{array}$ & $\begin{array}{l}\text { INCLUSÃO OU } \\
\text { DIVISÃO }\end{array}$ \\
\hline 04 & $\begin{array}{l}\text { "Afinal, sociologia é uma matéria super ampla, onde discutimos desde a } \\
\text { economia do país a transtornos psicológicos" - Estudante J }\end{array}$ & $\begin{array}{l}\text { IDENTIDADE E } \\
\text { DEFINIÇÃO }\end{array}$ \\
\hline 05 & $\begin{array}{l}\text { "No entanto, o coordenador Geral da Campanha Nacional pelo Direito à } \\
\text { Educação (CNDE), Daniel Cara, as medidas criam uma cortina de fumaça para } \\
\text { o cerne do problema. } \\
\text { 'Essa reforma é uma falácia, porque não resolve as questões estruturais, como } \\
\text { a formação de professores e pontos que eram demandas dos estudantes que } \\
\text { ocuparam as escolas, como a redução do número de alunos por classe. De } \\
\text { nada adianta ênfase em exatas ou humanidades, se o professor for mal } \\
\text { preparado, se não houver recurso', afirma." - Estudante J }\end{array}$ & AUTORIDADE \\
\hline 06 & $\begin{array}{l}\text { "por isso acredito que para haver uma reforma dessa deveriam melhorar a } \\
\text { qualidade de ensino em todo país primeiro" - Estudante G }\end{array}$ & CONDIÇÃO \\
\hline 07 & $\begin{array}{l}\text { "a possibilidade de contratar professores sem diplomas de licenciatura, mas } \\
\text { que apresentem "notório saber" na área que ensinarão - muitas escola ja tem } \\
\text { isso, falo por experiência própria, tinha uma professora de inglês que mal sabia } \\
\text { português." - Estudante N }\end{array}$ & ILUSTRAÇÃO \\
\hline
\end{tabular}

Fonte: Os autores

$\mathrm{O}$ argumento de sucessão elaborado pelo estudante $\mathrm{H}$ evidencia os principais efeitos da reforma do ensino médio, estabelecendo uma relação de causalidade entre a medida provisória (causa) e seus respectivos benefícios (efeitos) apresentados de forma sucessiva. Outro argumento também produzido pelo estudante $\mathrm{H}$ é o que estabelece uma divisão,

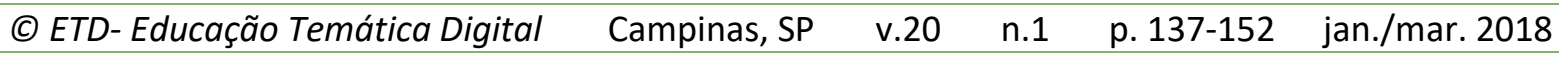


especificando os componentes para uma boa formação do cidadão. $\mathrm{O}$ estudante $\mathrm{K}$ formula um argumento de contradição e incompatibilidade, apresentando sentenças opostas no jogo argumentativo que se referem à reforma para melhoria do ensino médio e ao corte de gastos na educação. Por sua vez, o estudante J apresenta um argumento bastante usual que é o da identidade e definição, que estabelece uma relação de significação e apresenta características de um dado termo, o que ele faz com a disciplina Sociologia, por exemplo. Outro argumento muito utilizado é o de autoridade, apresentado também pelo estudante J, que se baseia na citação de especialista na área ou uma instituição de pesquisa. 0 estudante $\mathrm{G}$ traz um argumento de condição, expondo em seu enunciando um requisito (melhoria da qualidade de ensino) para que algo aconteça (a reforma do ensino médio). Por fim, o estudante $\mathrm{N}$ apresenta um argumento de ilustração, discorrendo sobre uma experiência própria para ilustrar a discussão acerca da possibilidade de contratação de professores sem licenciatura. É importante destacar que a ilustração se difere do exemplo por retratar uma situação conhecida e comumente aceita, como a atuação de professores sem formação específica em muitas partes do Brasil.

Assim, os argumentos construídos pelos estudantes na discussão da temática proposta são variados, marcam seus pontos de vista no processo argumentativo e podem, também, ser considerados como jogos de linguagem, pois se constituem como enunciados diferenciados, produzidos num contexto específico entre enunciadores e destinatários e utilizados como lances nas práticas sociais de uso da linguagem.

\section{CONSIDERAÇÕES FINAIS}

Na sociedade pós-moderna observamos como a construção, a disseminação e a legitimação dos conhecimentos sofreram transformações, especialmente em meio ao desenvolvimento de novas tecnologias da informação, comunicação e expressão. Nessa conjuntura de modificação do conhecimento e, consequentemente, das relações de ensino e aprendizagem, os professores podem explorar potencialmente as TICE em suas atividades pedagógicas para oferecer aos estudantes um aprendizado contextualizado com suas práticas sociais cotidianas.

Em relação ao ensino de língua materna, notamos como as mídias sociais digitais, utilizadas por muitos estudantes e professores em seu dia a dia, podem ser usufruídas em práticas pedagógicas para o desenvolvimento das capacidades de leitura e escrita, possibilitando o contato com múltiplas linguagens, promovendo análises intertextuais, estabelecendo novas formas de interação e aproveitando os espaços de escrita online para o estímulo à produção textual.

Tendo em vista o questionamento e o objetivo iniciais propostos neste estudo, a análise dos resultados apontou que é possível utilizar os espaços de escrita online oferecidos por diversas mídias sociais digitais, como o WhatsApp, por exemplo, para o 
desenvolvimento da argumentação dos estudantes, estimulando-os a discutirem, a compartilharem links de acesso à informação, a apresentarem um posicionamento crítico e a construírem diversos argumentos para defendê-lo. No processo argumentativo das discussões realizadas, os enunciados construídos são diversos, configurando-se como verdadeiros jogos de linguagem produzidos de forma natural e utilizados como lances numa partida.

A capacidade de argumentação estimulada e desenvolvida no ambiente das mídias pode auxiliar os estudantes na produção de diferentes gêneros argumentativos em seu cotidiano, como um artigo de opinião, uma dissertação escolar, uma carta de leitor, uma carta de reclamação ou de solicitação, um fórum ou um chat, que também podem assumir características argumentativas.

Em suma, espera-se que a proposta de atividade pedagógica aqui apresentada possa ser aplicada por outros professores, adaptando-a e a aprimorando de acordo com o seu alunado e contexto de trabalho, ou até mesmo possa inspirar a formulação de outras propostas que possibilitem o ensino e a aprendizagem de língua materna mediados pelas diversas ferramentas das mídias sociais digitais.

\section{'REFERÊNCIAS}

BARDIN, Laurence. Análise de Conteúdo. Lisboa, Portugal: Edições 70, LDA, 2009.

BARTON, David; LEE, Carmen. Linguagem online: textos e práticas digitais. São Paulo: Parábola Editorial, 2015.

CARVALHO MARTINS, Erikson de. O Fórum e o Chat no Facebook: uma proposta pedagógica para o desenvolvimento da argumentação na produção textual. 2015. 174 fls. Dissertação (Mestrado em Letras). Universidade do Estado da Bahia: Santo Antônio de Jesus -BA.

FRANCO, Maria Laura Puglisi Barbosa. Análise de conteúdo. 2 ed. Brasília: Liber Livro Editora, 2003.

KENSKI, Vani Moreira. Tecnologias e ensino Presencial e a Distância. Campinas: Papirus, 2003.

KENSKI, Vani Moreira. Tecnologias e tempo docente. Campinas: Papirus, 2013.

LEITÃO, Selma. O lugar da argumentação na construção do conhecimento em sala de aula. In: LEITÃO, Selma; DAMIANOVIC, Maria Cristina. Argumentação na escola: O conhecimento em construção. Campinas-SP: Pontes Editores, 2011. p.13-46.

LYOTARD, Jean-François. A condição pós-moderna. 15. ed. Rio de Janeiro: Editora José Olympio, 2013.

PERELMAN, Charles; OLBRECHTS-TYTECA, Lucie. Tratado da argumentação: a nova retórica; Trad. Maria Ermantina de Almeida Prado Galvão; 2. ed. - São Paulo: Martins fontes, 2005.

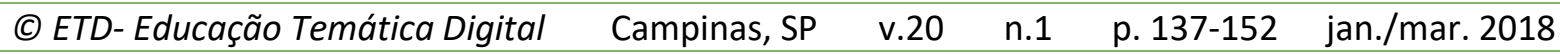


THIOLLENT, Michel. Metodologia da pesquisa-ação. São Paulo: Cortez: Autores Associados, 2002.

UMBELINA, Vanessa. Redes sociais: Aliadas ou vilãs da educação. Hipertextus Revista Digital, n.9, Dez. 2012. Disponível em: http://www.hipertextus.net/volume9/08Hipertextus-Vol9-Vanessa-Umbelina.pdf Acesso em: 12 nov. 2016.

WITTGEINSTEIN, Ludwig. Investigações filosóficas. 10ạ ed. São Paulo: Editora Nova Cultural, 1999.

XAVIER, Antônio Carlos; LYRA, Ilka Werkhäuser. Das redes sociais à sala de aula: As expressões nominais como estratégias de referenciação criativa e de argumentação na produção textual. Hipertextus Revista Digital, n.8, Jun. 2012. Disponível em: http://www.hipertextus.net/volume8/07-Hipertextus-Vol8-Antonio-Carlos-Xavier \& IlkaWerkh\%C3\%A4user-de-Lyra.pdf Acesso em: 12 nov. 2016.

\footnotetext{
'Revisão gramatical e ortográfica sob a responsabilidade de: Erikson de Carvalho Martins; professor de Língua Portuguesa do Instituto Federal da Bahia, Campus Barreiras, mestre em Letras pela Universidade do Estado da Bahia. E-mail: eriksonecm@hotmail.com
} 